\title{
Frozen elephant trunk with Frozenix prosthesis
}

\author{
Yutaka Okita ${ }^{1,2}$ \\ ${ }^{1}$ Cardio-Aortic Center, Takatsuki General Hospital, Osaka, Japan; ${ }^{2}$ Division of Cardiovascular Surgery, Department of Surgery, Kobe University, \\ Kobe, Hyogo, Japan \\ Correspondence to: Yutaka Okita, MD. Cardio-Aortic Center, Takatsuki General Hospital, Kosobe 1-3-13, Takatsuki, Osaka 569-1192, Japan. \\ Email: yutakaokita@gmail.com.
}

\begin{abstract}
This paper presents the clinical applications of the Japanese-made frozen elephant trunk (FET, Frozenix ${ }^{\circledR}$ ). The historical aspects of FET development, manufacture and structure of Frozenix, video images of a representative case, and a summary of a multi-centre Japanese Frozenix study, J-ORCHESTRA, are discussed.
\end{abstract}

Keywords: Total arch replacement; frozen elephant trunk (FET); selective antegrade cerebral perfusion; acute aortic dissection; brain malperfusion; distal aortic aneurysm

Submitted Dec 10, 2019. Accepted for publication Mar 16, 2020.

doi: $10.21037 /$ acs.2020.03.13

View this article at: http://dx.doi.org/10.21037/acs.2020.03.13

\section{Introduction}

Recent advances in endovascular treatment for thoracic aortic disease have widened surgical indications by reducing the complexity and invasiveness of surgical procedures. The frozen elephant trunk (FET) procedure has emerged as a means of facilitating not only distal lumen thrombosis, but also easier distal aortic anastomosis during total arch replacement $(1,2)$. Clinical applications of the FET cover a broad spectrum of thoracic aortic disease, including extensive arch and descending aneurysms, and acute or chronic DeBakey type I aortic dissection (3). Several commercially-made FET grafts are currently available (4-6).

\section{Current data on arch surgery in Japan}

Between 1996 and 2016 there has been an increase in the number of elective open aortic arch surgeries, including hemiarch and total arch replacement (TAR) in Japan (Figure 1) $(7,8)$. The number of surgeries was 903 in 1996, increasing to 2,542 in 2016 . Mortality was $21.6 \%$ in 1996 and improved to $5.0 \%$ in 2016 . The right panel shows trends in open surgery for acute aortic dissection. The number of surgeries was 485 in 1996 and increased to 1,642 in 2016. Mortality was $29.1 \%$ in 1996 and improved to $11.9 \%$ in 2016 . A study of the national Japanese Cardiovascular Surgery Database (JCVSD), showed that elective aortic arch surgeries were performed in 6,309 patients during 2015 and 2016. Hospital death occurred in $5.3 \%$ of patients, new stroke occurred in $6.9 \%$, and renal failure requiring dialysis occurred in 5.1\% (Figure 2).

\section{History of FET}

In 1983, Borst et al. introduced the two-stage elephant trunk principle as a surgical treatment strategy for extensive thoracic aortic disease (6). This approach is based on the prosthetic replacement of the whole arch with an elephant trunk extension of the arch graft inserted into the descending aorta during the first stage operation, performed through a median sternotomy. However, the graft segment forming the elephant trunk is free-floating in the descending aortic lumen, thus impeding thrombus formation between the graft and the aneurysmal vessel wall. This method intrinsically requires a second stage operation, performed through a left thoracotomy.

In 1996, Kato et al. (1) first reported ten patients who had undergone home-made stent-graft insertion in an aneurysmal descending aorta or the true lumen in the case of a dissected descending aorta. All patients had a median sternotomy, and cardiopulmonary bypass (CPB) under deep hypothermia was instituted. The stent-graft was constructed with a self-expanding (Gianturco ${ }^{\circledR}$ ) stent that is anchored into the woven Dacron graft $\left(\mathrm{UBE}^{\circledR}\right.$, Japan). Complete 
A

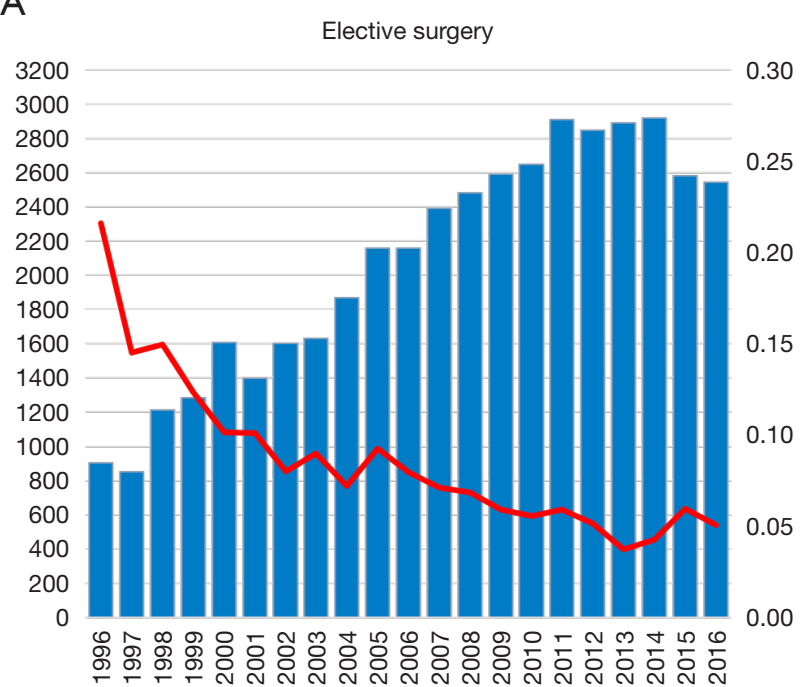

B

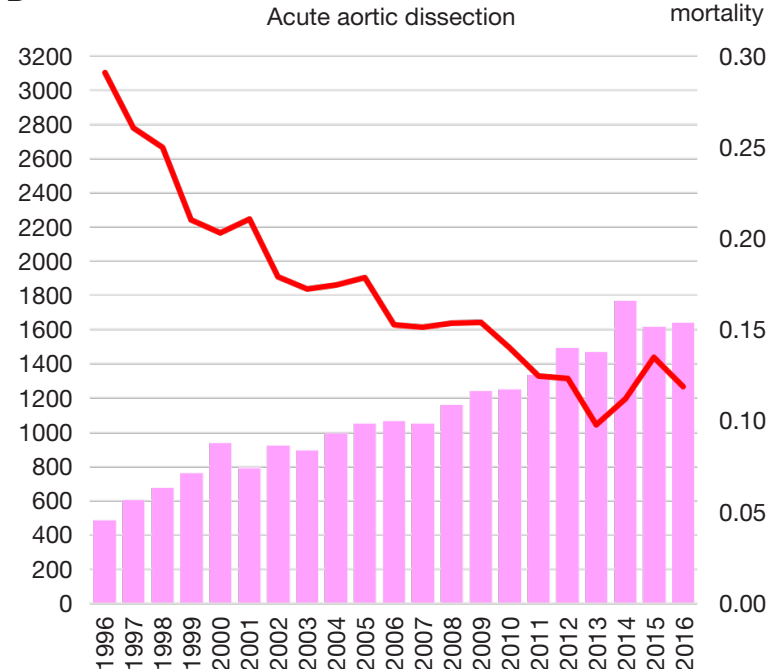

Figure 1 Open arch surgery in Japan, JATS survey. (A) Elective surgery for the aortic arch, (B) surgery for acute type A aortic dissection.

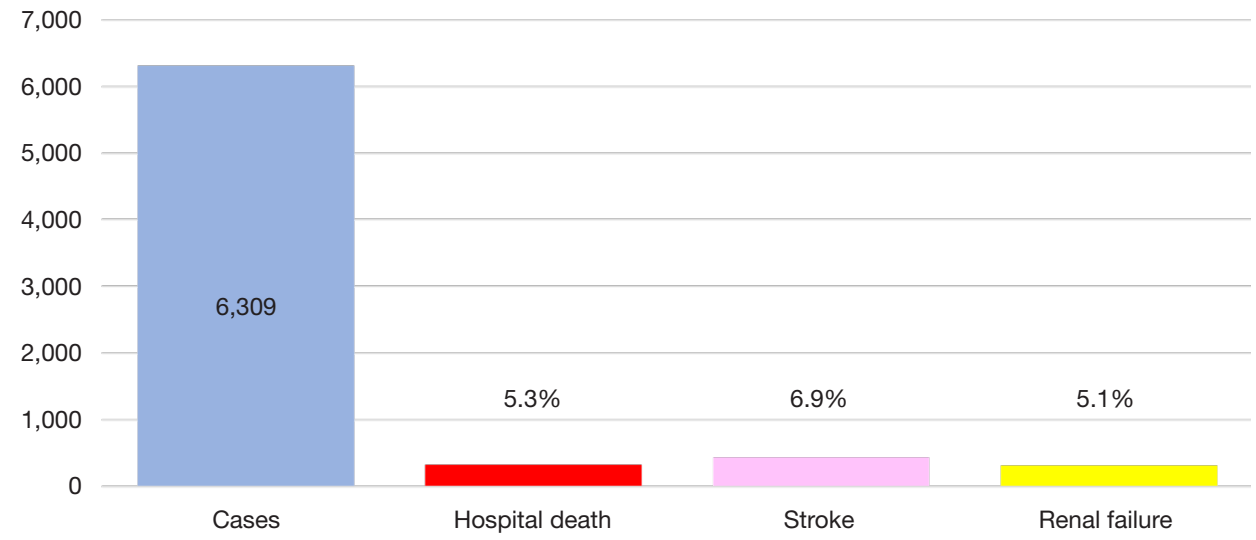

Figure 2 Arch surgery in Japan excluding acute aortic dissection, ruptured aneurysm, JCVSD (Japanese Cardiovascular Surgery Database) database: 2015-2016.

thrombosis of the aneurysms or false lumens surrounding the grafts occurred in all ten patients. This showed that it was possible to avoid a second operation requiring a left thoracotomy. They named this method "open stent grafting".

In 2003, Karck et al. (2) reported four patients with aneurysms of the descending aorta or chronic aortic dissection, who had open aortic arch replacement with stent-graft insertion in the descending aorta. They used a custom-made stent-graft (Chavan-Haverich ${ }^{\circledR}$, Curative Medical Devices Gmbh, Dresden). They found complete thrombosis in the descending aorta or false lumen around the stent-graft. This was the first report where this method was called "frozen elephant trunk (FET)".

Since then, the FET procedure has been widespread mainly in Europe, and many clinical investigations have been reported using commercially-made products (7-9). This procedure virtually excludes the need for surgical replacement of the descending aorta, and the majority of patients who had FET at the first stage had the subsequent endovascular stent-graft inserted in the descending aorta. However, not all patients show a decrease in the size of the aneurysm in the descending aorta and problems in the thoracoabdominal aortic portion are not solved by this technique.

In China, Sun and colleagues developed their own FET, 


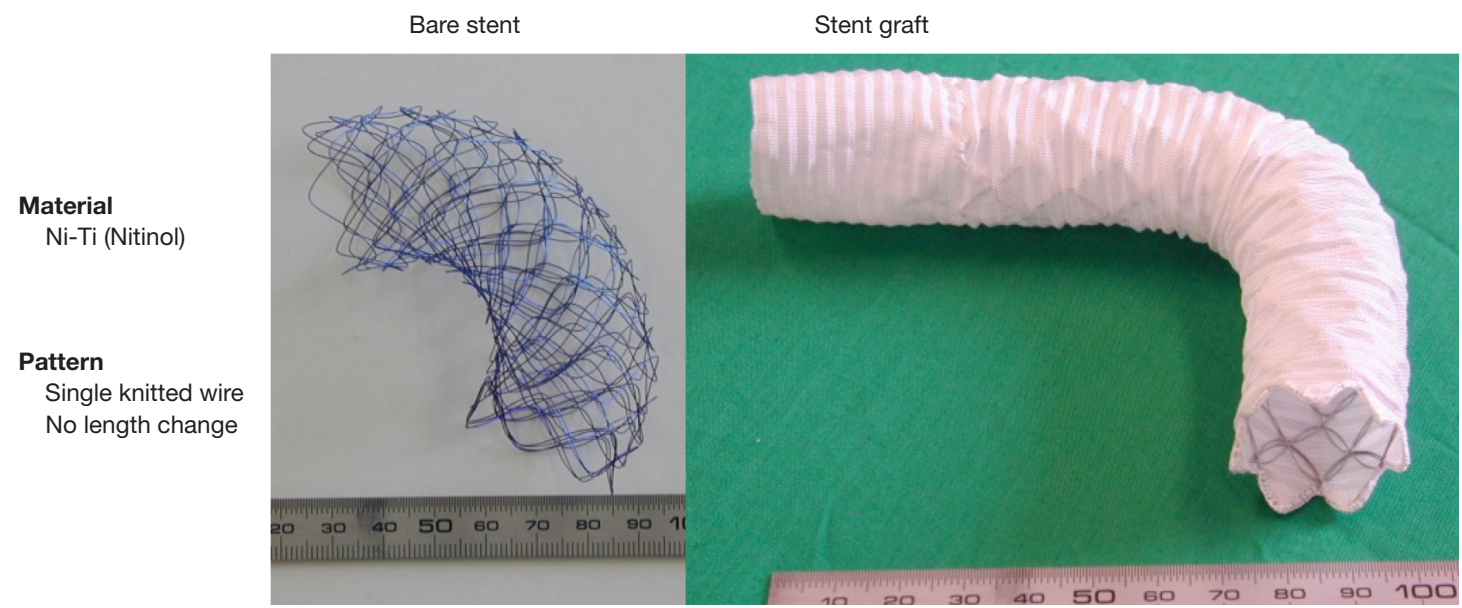

Figure 3 Frozenix ${ }^{\circledR}$, graft fabric and internal skeleton.

which is similar to Kato's original FET, and is mainly used for patients with acute type A aortic dissection (10).

\section{Japan-made FET: Frozenix}

A Japan-made FET prosthesis (J graft Frozenix ${ }^{\circledR}$, Japan LifeLine, Tokyo) was first launched in 2014. The Dacron graft has external velour with a thickness of $300 \mu \mathrm{m}$ and its water porosity is $150 \mathrm{~mL} / \mathrm{cm}^{2}$.

The prosthesis consists of a Dacron polyester fabric vascular prosthesis with Nitinol stents affixed on the inner aspect. The Nitinol stent is hand-knitted to maintain its length even with changes in diameter. The stent is entirely covered with the Dacron prosthesis. The proximal portion of the Frozenix stent graft is composed of a simple Dacron graft (Figure 3).

The delivery system consists of a malleable rod (10 Fr) that can be advanced into the descending aorta over a 0.035 -inch flexible guide wire. The system is wrapped in a smooth-surfaced polyester mesh. The sheath has markers at $1 \mathrm{~cm}$ intervals in the non-stented portion, with the last marker meant to be positioned at the edge of the distal aorta.

As the stent has a constant length, the distal end of the stent-graft can be fixed as required. Withdrawal of the outer sheath while the inner rod is held steady releases the stented portion of the Frozenix stent-graft. The proximal Dacron tube can then be released by simply pulling back both the sheaths and rod. No balloon modulation to accommodate the stent-graft in the descending aorta is necessary.

The main advantages of Frozenix are easier handling and implantability, and better conformation to the curvature of the aortic arch.

Frozenix was first launched in 2014 and more than 12,000 prostheses have since been implanted. The etiologies of the treated aortic lesions were degenerative aneurysms in $43 \%$ of patients, acute type A aortic dissection in $42 \%$, chronic type A dissection in $3 \%$, acute type B dissection in $2 \%$, and chronic type B dissection in $8 \%$.

The size of the Frozenix stent graft is chosen to match the diameter of the descending aorta or the diameter of the true lumen. The products have a range of diameters from 21 to $39 \mathrm{~mm}$ ( $2 \mathrm{~mm}$ increments), and the length of the stented portion can be $6,9,12$, or $15 \mathrm{~cm}$. In 2019 almost $80 \%$ of patients had a 9 or $12 \mathrm{~cm}$ long Frozenix.

Of the Frozenix stents used in patients with acute aortic dissection, 24\% were $6 \mathrm{~cm}$ long, 55\% were $9 \mathrm{~cm}$ long, and $20 \%$ were $12 \mathrm{~cm}$ long. The majority of the patients had Frozenix grafts 25 to $29 \mathrm{~mm}$ in diameter (Figure 4). On the other hand, in patients with non-dissection degenerative aneurysm, $39 \%$ were $9 \mathrm{~cm}$ and $47 \%$ were $12 \mathrm{~cm}$ in stent length and the diameter was much larger than in the acute dissection group (Figure 5).

\section{Reported studies}

Table 1 shows a recent clinical summary of FET experiences. The aortic lesions include degenerative aneurysm and acute or chronic aortic dissection. The rate of early death ranges from $2.4 \%$ to $14.9 \%$, and the rate of permanent stroke ranges from $2.6 \%$ to $10.8 \%$. Newly developed permanent paraplegia occurs in $1.2 \%$ to $5.5 \%$ of patients $(4,9-19)$. 

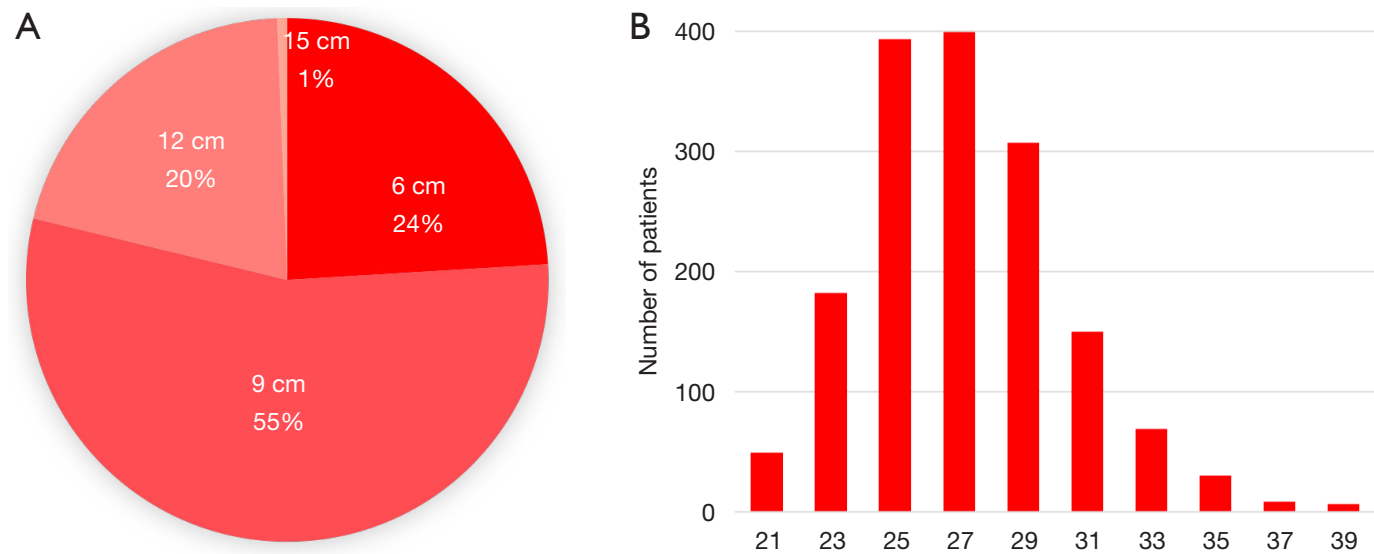

Figure 4 Frozenix ${ }^{\circledR}$ in the market for Acute Aortic Dissection, (A) graft size, length, (B) graft size, diameter.
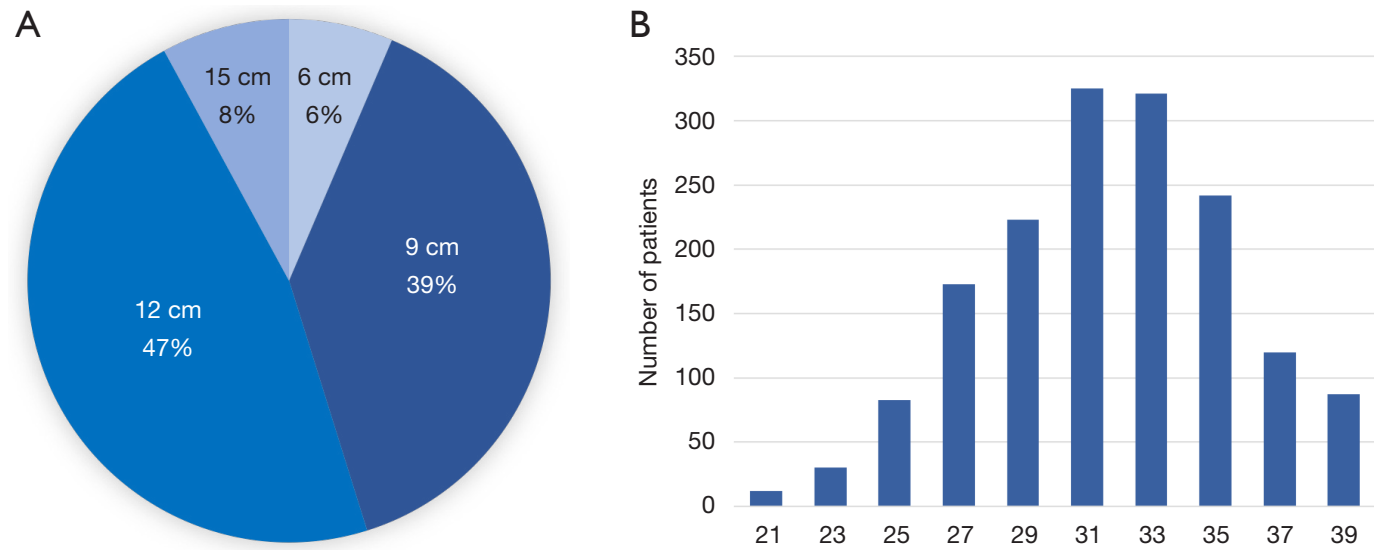

Figure 5 Frozenix ${ }^{\circledR}$ in the market for Non-dissecting Aneurysm, (A) graft size, length, (B) graft size, diameter.

\section{Cases}

The first case discussed here is of a 42-year-old female with a history of previous renal transplantation, presenting with an acute DeBakey type I aortic dissection. Although no abnormal neurological signs were detected, a $40-\mathrm{mmHg}$ systolic pressure difference was noted between the upper arms.

Preoperative CT scan showed a DeBakey type I aortic dissection. The brachiocephalic artery (BCA) was not opacified, and an aberrant left subclavian artery branched directly from the aortic arch.

A total arch replacement was conducted as follows. Arterial return was provided with direct cannulation of the right femoral artery, as well right axillary artery return provided by an anastomosed $8 \mathrm{~mm}$ Dacron graft. Cerebral protection was achieved using moderate hypothermic circulatory arrest combined with antegrade cerebral perfusion (ACP).

After mid-sternotomy, the innominate vein was fully mobilized. Dissection of the aneurysm, aortic arch branches and the vagal nerve was not attempted. No taping around the arch or arch vessels was applied. The $\mathrm{CPB}$ was established using the femoral and axillary artery cannulations. Because the right cerebral oxygen saturation $\left(\mathrm{rSO}_{2}\right)$ was still lower than the left, the BCA was also perfused using a $15 \mathrm{Fr}$ intraluminal balloon-tipped catheter immediately after starting CPB. The skin incision was extended to the left infraclavicular fossa, and the left subclavian artery (LSCA) was taped medial to the left common carotid artery (LCCA). An aberrant left vertebral artery branched directly from the arch between the LCCA 


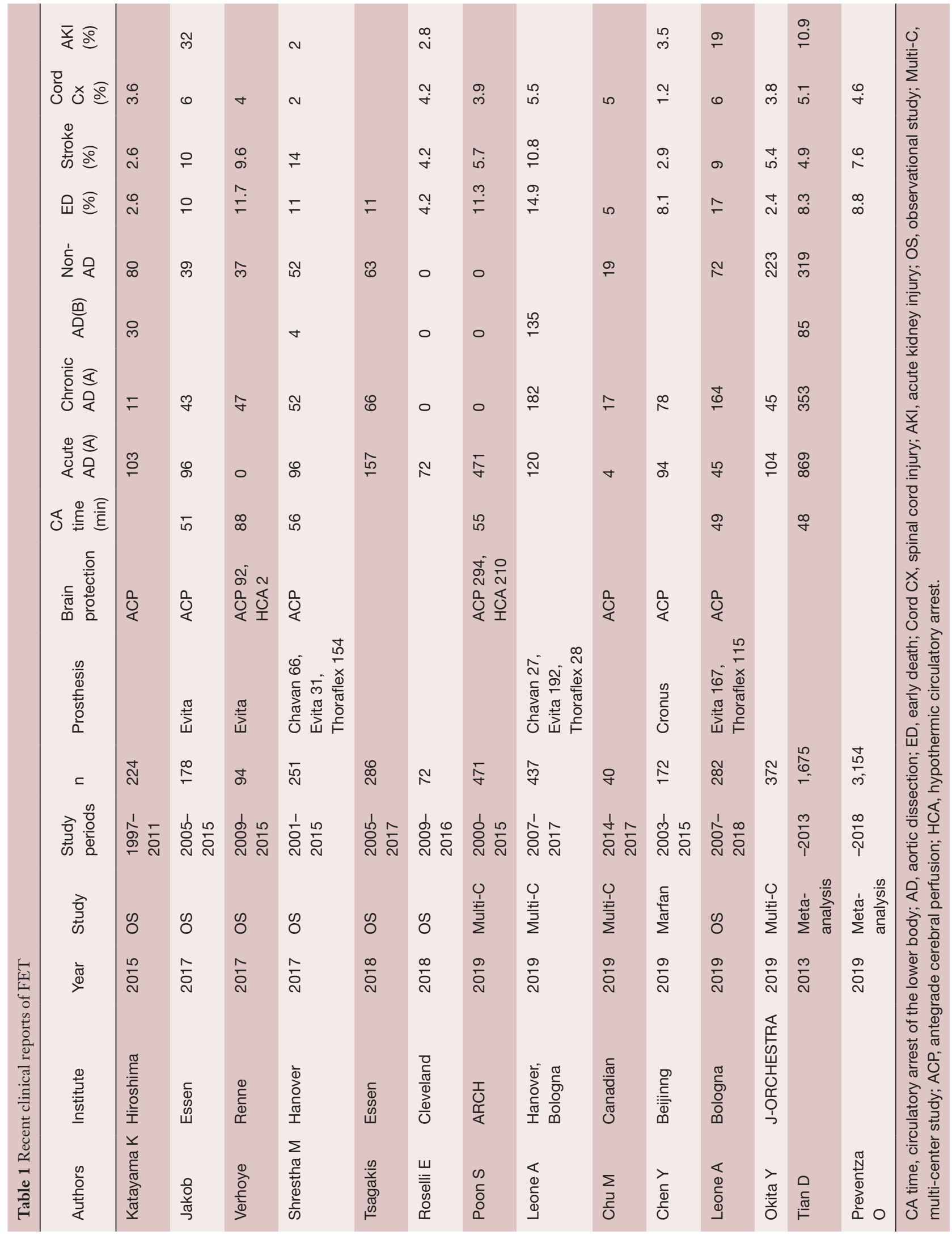


and the LSCA.

Core cooling was performed until both tympanic temperatures went down to $23{ }^{\circ} \mathrm{C}$ and rectal temperature went down to $30^{\circ} \mathrm{C}$. Total circulatory arrest was performed with CVP rising to $5 \mathrm{mmHg}$. The heart was arrested by infusion of retrograde cardioplegia solution. The aortic cannula was removed, and the aortic arch was opened longitudinally. A 2-cm circumferential intimal tear was found distal to the LSCA. A 12 Fr balloon-tipped cannula (Sumitomo Bakelite, Akita) was inserted to the LSCA and LCCA from inside the arch. The aberrant left vertebral artery was clamped. ACP was started using a single roller pump with a flow of 10 to $12 \mathrm{~mL} / \mathrm{kg} / \mathrm{min}$. The perfusate temperature was kept at $23{ }^{\circ} \mathrm{C}$. The left and the right radial pressures, as well as the line pressure of the balloon catheters, were monitored to keep the pressure between 30 and $50 \mathrm{mmHg}$. Cerebral oxygen saturation $\left(\mathrm{rSO}_{2}\right)$ was monitored bilaterally from the forehead using near-infrared spectroscopy.

A button incorporating the LCCA and the aberrant left vertebral artery was made, and the arch was transected at zone II (between LCCA and LSCA). The size of the true lumen of the descending aorta was measured using a ball caliper. The LSCA was transected at its origin, and a $12 \mathrm{Fr}$ cannula was re-inserted into the distal lumen. The proximal stump of the LSCA was oversewn using a buttressed 3-0 polypropylene suture (Prolene ${ }^{\circledR}$, Ethicon, USA).

A FET (J graft Frozenix ${ }^{\circledR} 21 \mathrm{~mm} \times 12 \mathrm{~cm}$, Japan LifeLine, Tokyo) was prepared. A gentle curve was made at the stent-graft portion of the FET to conform to the shape of the aortic arch and descending aorta. The descending aorta was filled with blood, and the FET was introduced into the true lumen of the descending aorta. The marker of the FET was set to the proximal edge of the descending aorta. The FET was deployed by pulling the sheath proximally while monitoring the TEE. The sheath of the FET, guiding rod, and guiding wire were removed. A nonstented portion of the FET was resected, and the FET was fixed at the descending aorta with Teflon felt reinforcement using three mattress 4-0 polypropylene sutures (Nespilene ${ }^{\circledR}$, Alfresa, Tokyo).

A 24-mm 4-branched Dacron graft (Triplex graft ${ }^{\circledR}$, Terumo, Tokyo) was anastomosed to the stump of the descending aorta, incorporating the FET and Teflon felt using a long 3-0 monofluorvinylydene suture (Monofulene ${ }^{\circledR}$ $120 \mathrm{~cm}, 24 \mathrm{~mm}$ needle; Alfresa, Japan). A flexible sucker was placed inside the graft to suck the blood in the descending aorta. Initially, the suture was placed at 9 o'clock in the graft, FET, aorta, and Teflon strip. After tying down, the suture went counterclockwise. Initially, the needle was carried forehand. From the 3 o'clock position, the direction of the needle was changed to a reverse manner. After finishing the anastomosis and filling the descending aorta with blood, antegrade perfusion of the lower body was slowly started through the $4^{\text {th }}$ side branch of the graft. Rewarming was then started. Coincident with re-warming, antegrade SCP flow was gradually increased while maintaining the baseline values of $\mathrm{rSO}_{2}$. However, antegrade SCP flow was limited to below $1,200 \mathrm{~mL} / \mathrm{min}$ to prevent brain edema.

The ascending aorta was transected $1 \mathrm{~cm}$ above the ST junction. A $5 \mathrm{~mm}$ width graft strip was placed inside the proximal lumen and fixed with 3 mattress sutures with an outer Teflon strip. A small amount of Bioglue ${ }^{\circledR}$ was placed in the proximal false lumen. A continuous horizontal mattress suture was made to close the false lumen. The four-branch graft was anastomosed to the ascending aorta using a monofluorvinylydene suture (Monofulene ${ }^{\circledR} 120 \mathrm{~cm}$, $22 \mathrm{~mm}$ needle; Alfresa, Japan). After the deairing procedure, the graft clamp was released, and the heart was reperfused. Spontaneous beating of the heart soon resumed.

The LSCA was clamped and reconstructed to the graft branch using a 5-0, $17 \mathrm{~mm}$ needle polypropylene suture (Nespilene $^{\circledR}$, Alfresa, Japan). The button of the LCCA and the aberrant left vertebral artery was also anastomosed to the graft branch in the same manner. The balloon cannula was removed near the end of each anastomosis, and liberal backflow was used to flush the debris. As per usual, the parachute technique was used, and each vessel was perfused after completion of the anastomosis. Finally, the BCA was clamped and anastomosed.

With regard to regional oxygen saturation $\left(\mathrm{rSO}_{2}\right)$ of the forehead, the right $\mathrm{rSO}_{2}$ dropped significantly after initiating $\mathrm{CPB}$, but recovered soon after starting to perfuse the BCA. Duration of CPB was 159 minutes, cardiac ischemic time was 74 minutes, duration of circulatory arrest of the lower body was 34 minutes, and duration of ACP was 123 minutes. The minimum temperature of the tympanic membrane and rectum was $20.4^{\circ} \mathrm{C}$ and $24.6^{\circ} \mathrm{C}$, respectively. The postoperative course was straightforward. She was extubated on the same day. Postoperative CT scan showed a satisfactory result.

Some cases, however, can have have technical complications. Case 2 was a 43 -year-old male who had acute type A aortic dissection and underwent TAR with FET 
A

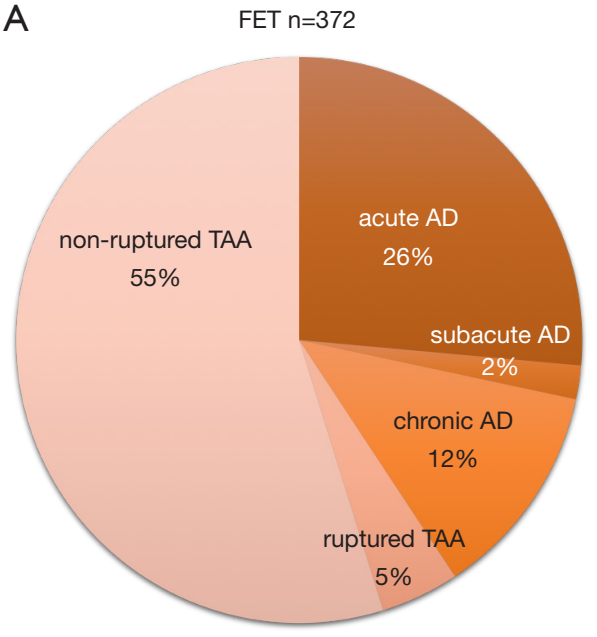

B

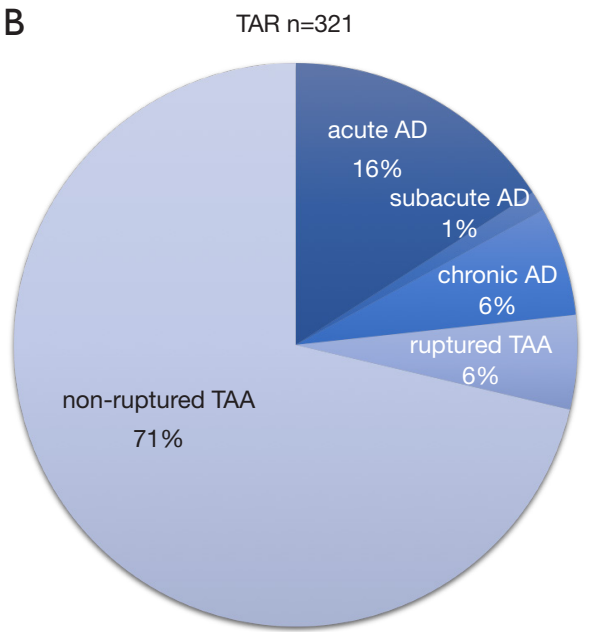

Figure 6 Aortic lesions in J-ORCHESTRA, (A) FET group, (B) non-FET group.

insertion. A 50-mmHg systolic pressure difference between the arms and legs was noted postoperatively. A right axillofemoral bypass was done using a $10 \mathrm{~mm}$ graft. Angiography showed a severe kinking of the non-stented portion of the FET. Immediately, a 25-mm stent-graft (Gore-Tag ${ }^{\circledR}$, W. L. Gore \& Associates, Co., LTD. Newark, USA) was inserted, and the pressure gradient disappeared.

The next case is a 76-year-old female who had chronic DeBakey type II aortic dissecting aneurysm and mega-aorta syndrome. The dissection commenced in the ascending aorta extending through the arch and descending aorta, which were also dilated with extensive mural thrombi. We did a TAR and FET using a 22-mm Triplex 4 branch graft and $25 \mathrm{~mm} \times 9 \mathrm{~cm}$ Frozenix. She was extubated on the same day; however, severe systemic embolization occurred the next day.

The last case is an 82-year-old male with an arch aneurysm, chronic type B aortic dissection, and severe aortic regurgitation. Preoperative CT showed an arch aneurysm and chronic type $\mathrm{B}$ dissection. We did an aortic valve replacement, TAR and FET using $25 \mathrm{~mm} \times 9 \mathrm{~cm}$ Frozenix. Postoperative CT showed that the FET was located in the false lumen in the descending aorta.

\section{J-ORCHESTRA study}

We conducted a multi-centre (41 institutions) prospective study (J-ORCHESTRA; J-Open caRdiac aortic arCH disEase replacement Surgical TheRApy Study) comparing clinical outcomes between patients who had TAR with
FET (FET group) and patients who had TAR with or without classical free elephant trunk (TAR group). The primary endpoint of this study was patient death. Secondary endpoints were cerebral complications such as stroke and temporary neurological dysfunction, spinal cord complications such as paraplegia, paraparesis, and incontinence, composite endpoints [severe adverse events (SAE); such as the brain, cardiac, spinal cord, respiratory, renal, bleeding, infection complications, and deaths], and aortic size in CT scans during follow-up. Forty-one institutions joined in this study and included 372 patients in the FET group and 321 patients in the TAR group from January 2016 to March 2019. The patients were followed up for 3 years.

Aneurysm lesions in patients in the FET group consisted of a degenerative aneurysm in $55 \%$, acute or subacute (surgery from 2 weeks to 2 months from the onset) aortic dissection in $28 \%$, chronic aortic dissecting aneurysm in $12 \%$, and ruptured aneurysm in $5 \%$. On the other hand, aortic lesions in the TAR group consisted of degenerative aneurysm in $71 \%$, acute or subacute aortic dissection in $17 \%$, chronic aortic dissecting aneurysm in $6 \%$, and ruptured aneurysm in 6\% (Figure 6).

The results (Table 2) showed that mean age at operation was 66.5 years in the FET group, which was younger than in the TAR group. Emergency surgery was more often performed in the FET group. Durations of CPB and cardiac ischemia were longer in the FET group, but in contrast, the duration of circulatory arrest of the lower body was shorter in the FET group. Hospital death occurred in 


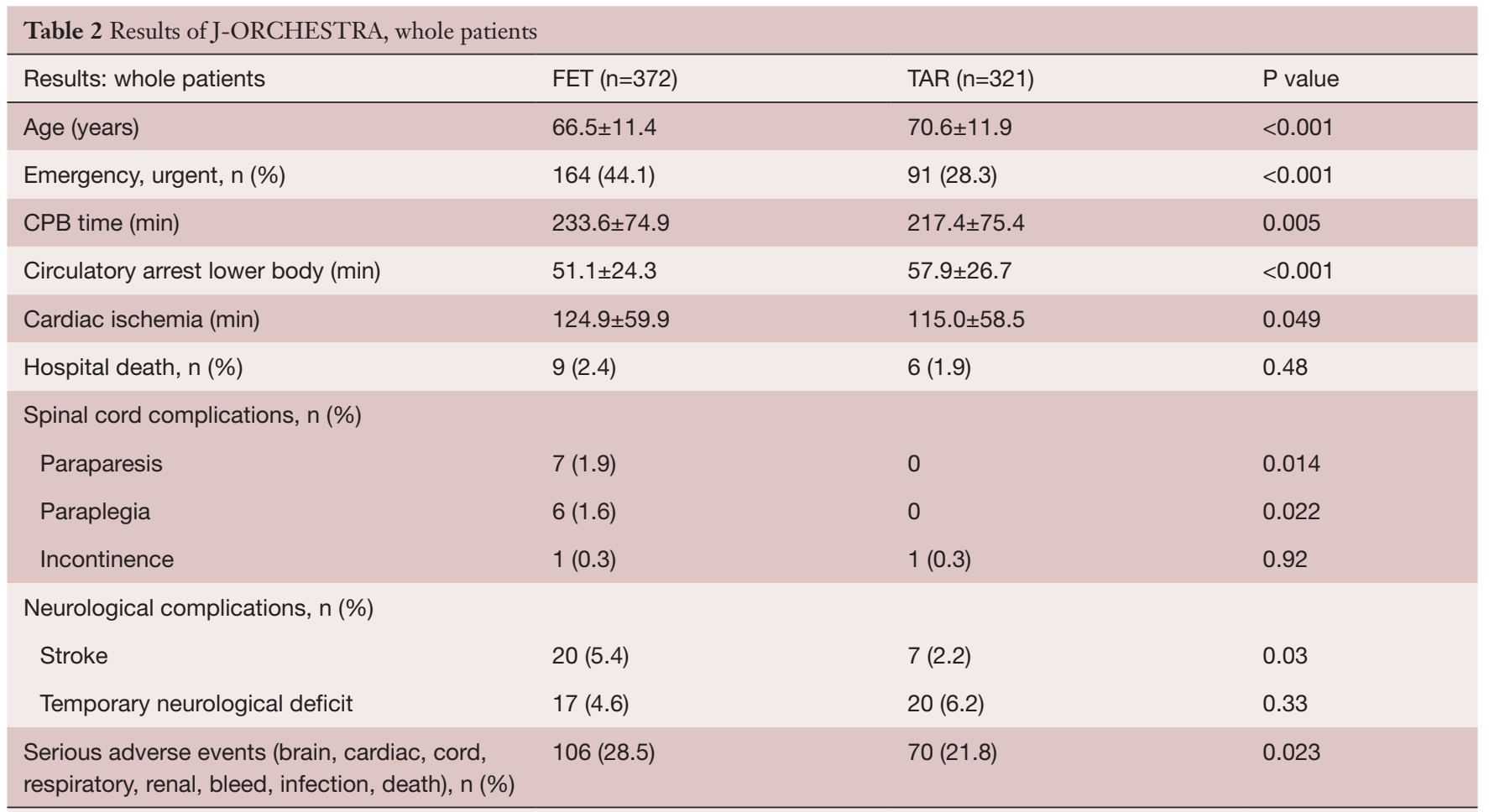

CPB, cardiopulmonary bypass; FET, frozen elephant trunk; TAR, total arch replacement.

$2.4 \%$ of patients in the FET group, and $1.9 \%$ in the TAR group. Postoperative new paraplegia occurred in 7 patients $(1.9 \%)$ and paraparesis in 6 patients $(1.6 \%)$ in the FET group, while no spinal cord complications were found in the TAR group. New stroke occurred more frequently in the FET group and as a result, serious adverse events were more frequent in the FET group.

Propensity score analysis was performed by matching data including patients' age and sex, presence of acute aortic dissection, emergency operation, chronic kidney disease, and method of brain protection (Table 3). We compared 230 patients in each group. The results showed that the only significant differences were shorter circulatory arrest time of the lower body and higher incidence of postoperative stroke in the FET group. Although the causes of the higher incidence of postoperative stroke in the FET group were not clear, we speculate that less-experienced surgeons may have performed the surgeries due to relative technical ease of distal anastomosis during the FET procedure.

Sixty percent of patients had the distal end of the Frozenix placed below T6 level, and 13\% had it below the T8 level. This may explain the higher incidence of postoperative spinal cord complications in the FET group

\section{(Figure 7).}

Red triangles show patients with acute aortic dissection who had paraplegia or paraparesis, and yellow triangles show patients with degenerative aneurysm. Eighty percent of patients who had spinal cord complications had the distal end of the FET below Th6 (Figure 8).

There was no relationship between the occurrence of spinal cord complications and duration of circulatory arrest of the lower body (Figure 9).

The majority of patients had moderate hypothermia between 20 and $30^{\circ} \mathrm{C}$. No significant relationship was found between the occurrence of spinal cord complications and body temperature (Figure 10).

The clinical advantage of FET is thought to be ease of handling the distal anastomosis in total arch replacement. This technique enables anastomosis in zone II, between the LCCA and LSCA, and can reduce the occurrence of left recurrent nerve palsy. In addition, bleeding from the distal anastomosis is seldom seen and there is less incidence of leakage to the distal false lumen occurs, resulting in positive remodeling of the distal aorta. However, some disadvantages of the FET do exist. The main concern in using this method is a relatively higher incidence of development 


\begin{tabular}{|c|c|c|c|}
\hline Results: propensity matching & FET $(n=230)$ & TAR $(n=230)$ & $P$ value \\
\hline CPB time (min) & $233 \pm 75$ & $221 \pm 77$ & 0.13 \\
\hline ACP time (min) & $129 \pm 58$ & $128 \pm 71$ & 0.90 \\
\hline Circulatory arrest lower body (min) & $51 \pm 25$ & $59 \pm 27$ & $<0.001$ \\
\hline Cardiac ischemia (min) & $137 \pm 56$ & $133 \pm 76$ & 0.72 \\
\hline Hospital death, n (\%) & $4(1.7)$ & $1(0.4)$ & 0.25 \\
\hline \multicolumn{4}{|l|}{ Spinal cord complications, n (\%) } \\
\hline Paraparesis & $3(1.3)$ & $0(0)$ & 0.082 \\
\hline Paraplegia & $3(1.3)$ & $0(0)$ & 0.082 \\
\hline \multicolumn{4}{|l|}{ Neurological complications, n (\%) } \\
\hline Stroke & $13(5.7)$ & $1(0.4)$ & 0.001 \\
\hline TND & $9(3.9)$ & $16(7.0)$ & 0.15 \\
\hline $\begin{array}{l}\text { Serious adverse events (brain, cardiac, cord, } \\
\text { respiratory, renal, bleed, infection, death), n (\%) }\end{array}$ & $103(44.8)$ & $107(46.5)$ & 0.71 \\
\hline
\end{tabular}

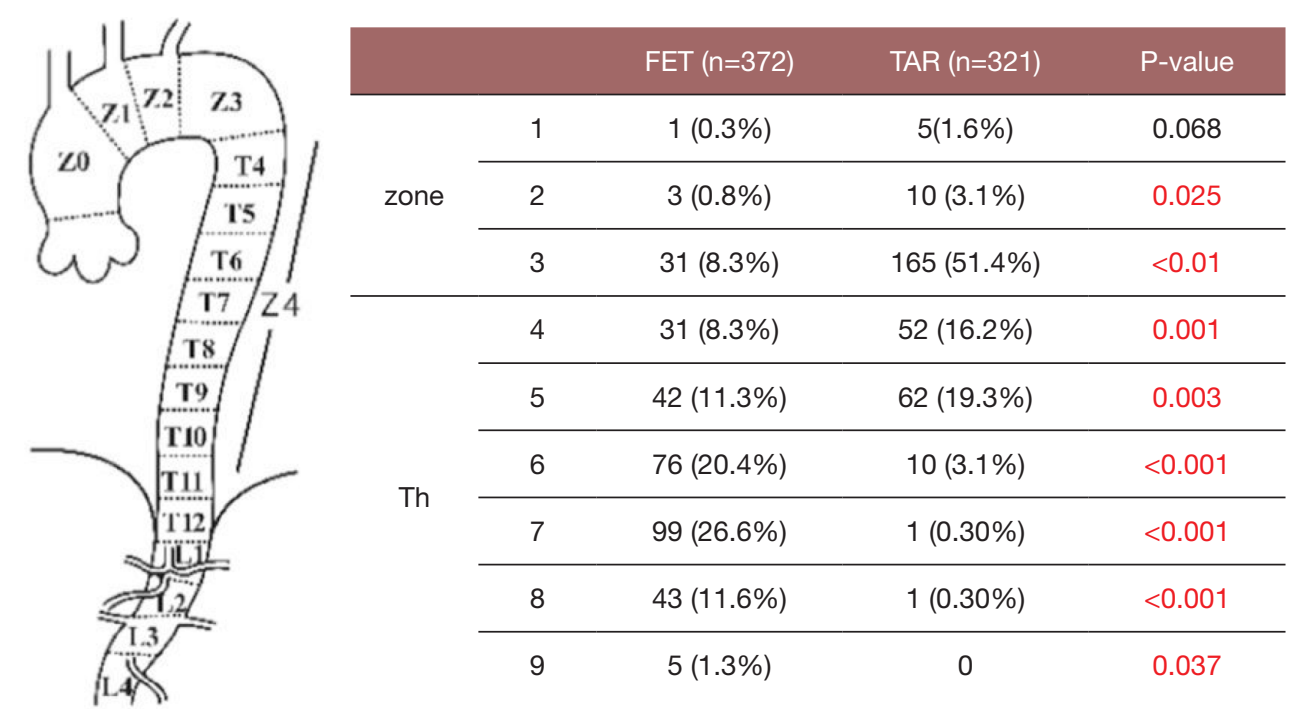

Figure 7 Location of FET tip, distal anastomosis.

of spinal cord ischemia (20). A recent survey showed an incidence of spinal cord ischemia of $1.7 \%$ in 4,600 patients. The J-ORCHESTRA study on the Frozenix disclosed a $3.8 \%$ incidence of postoperative spinal cord complications. Deliberate deployment of the distal stent-graft in the descending aorta above the level of the aortic valve should be considered to prevent spinal cord complications (21).
There have been some reports regarding the occurrence of stent-graft induced new entry (SINE), but we found that its incidence using the Frozenix was quite low because the Frozenix has an internal stent-skeleton. The occurrence of SINE can be alleviated by inserting the FET in a vertical position.

Current indications for FET usage are patients 


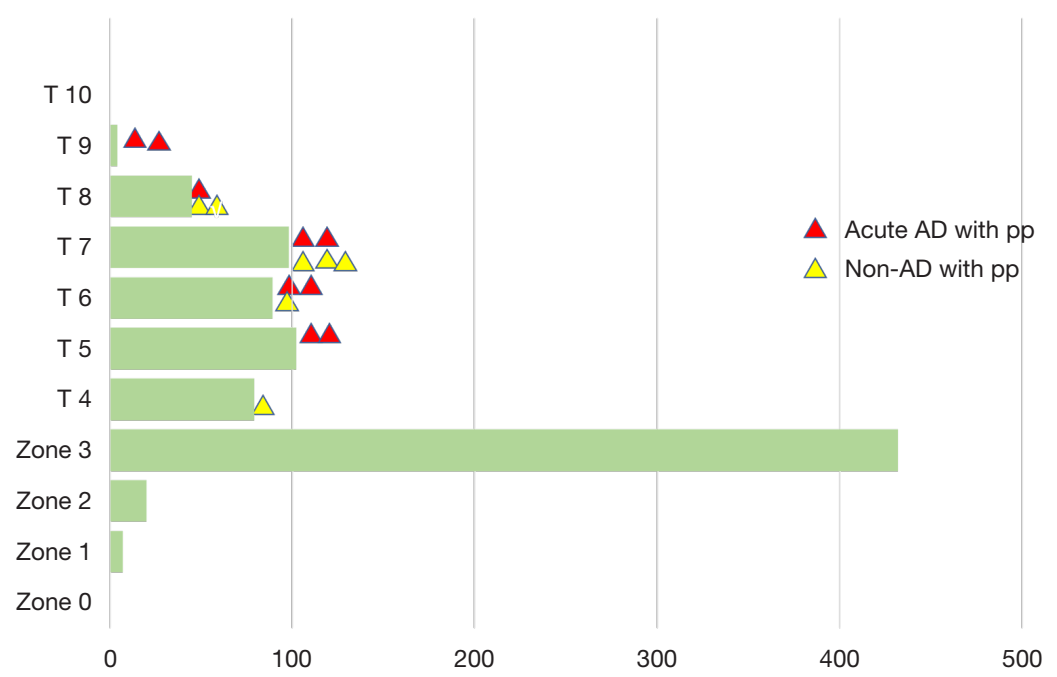

Figure 8 Zone tip. Red triangle; patients with acute aortic dissection complicated with spinal cord injury, yellow triangle; patients with nondissection complicated with spinal cord injury.

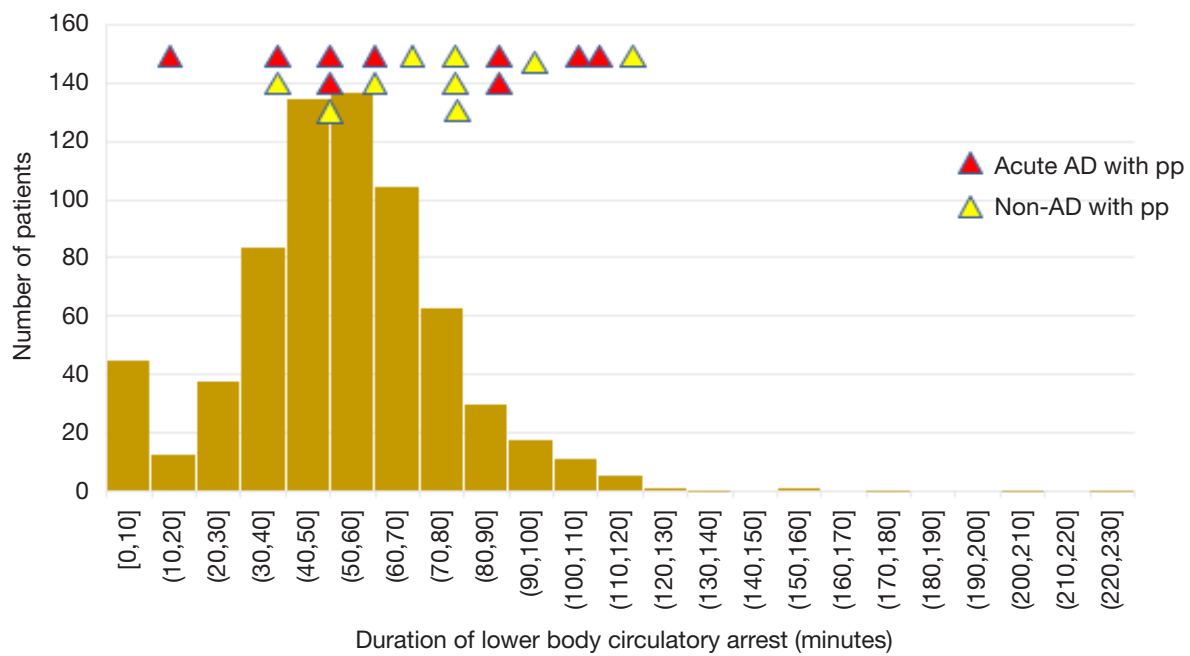

Figure 9 Circulatory arrest time of the lower body. Red triangle; patients with acute aortic dissection complicated with spinal cord injury, yellow triangle; patients with non-dissection complicated with spinal cord injury.

with acute type A aortic dissection who require TAR. Degenerative arch aneurysm or chronic aortic dissection with suitable anatomy are relative indications for FET. A shaggy descending aorta or presence of mega-aorta syndrome are contra-indications for FET usage.

\section{Conclusions}

Early outcomes after total arch replacement with/without
FET usage were satisfactory. The reported incidence of early death ranged from $2.4 \%$ to $14.9 \%$, and the incidence of permanent stroke ranged from $2.6 \%$ to $10.8 \%$. Newly developed permanent paraplegia occurred in $1.2 \%$ to $5.5 \%$ of patients. The J-ORCHESTRA study showed that incidence of postoperative spinal cord injury was higher in the FET group; however, the occurrence was less than $3 \%$. Duration of circulatory arrest of the lower body was shorter in the FET group. 


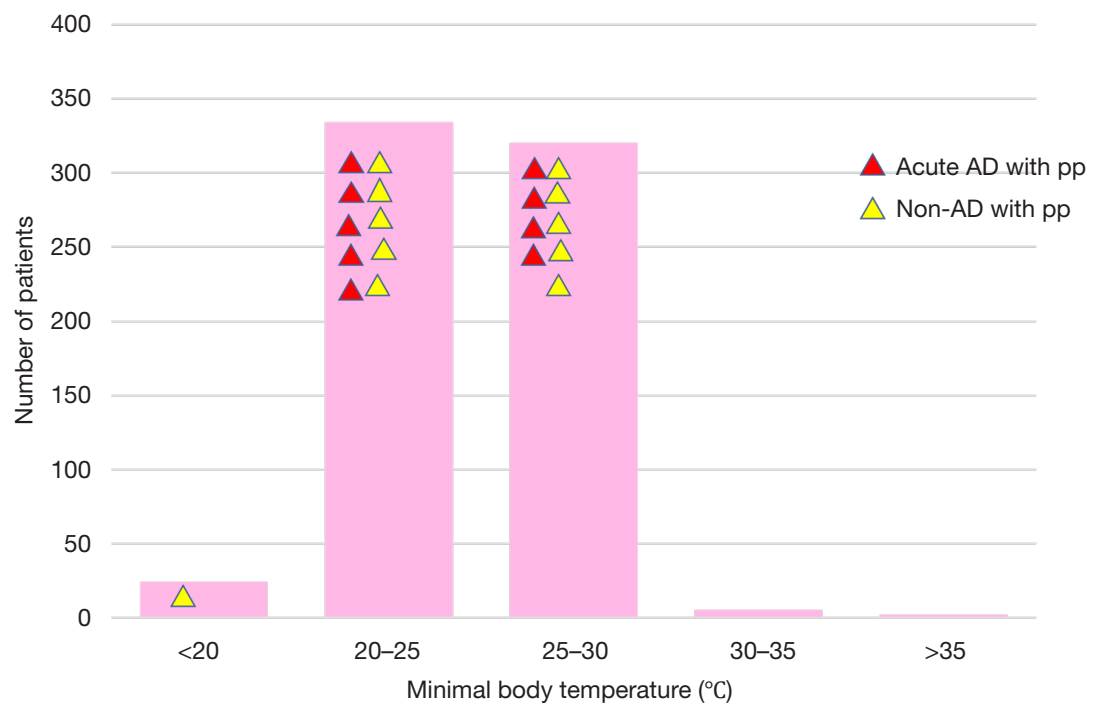

Figure 10 Minimum body temperature. Red triangle; patients with acute aortic dissection complicated with spinal cord injury, yellow triangle; patients with non-dissection complicated with spinal cord injury.

\section{Acknowledgments}

None.

\section{Footnote}

Conflicts of Interest: The author has no conflicts of interest to declare.

Open Access Statement: This is an Open Access article distributed in accordance with the Creative Commons Attribution-NonCommercial-NoDerivs 4.0 International License (CC BY-NC-ND 4.0), which permits the noncommercial replication and distribution of the article with the strict proviso that no changes or edits are made and the original work is properly cited (including links to both the formal publication through the relevant DOI and the license). See: https://creativecommons.org/licenses/by-nc-nd/4.0/.

\section{References}

1. Kato M, Ohnishi K, Kaneko M, et al. New graft-implanting method for thoracic aortic aneurysm or dissection with a stented graft. Circulation 1996;94:II188-93.

2. Karck M, Chavan A, Hagl C, et al. The frozen elephant trunk technique: a new treatment for thoracic aortic aneurysms. J Thorac Cardiovasc Surg. 2003;125:1550-3.

3. Easo J, Weigang E, Holzl PP, et al. Influence of operative strategy for the aortic arch in DeBakey type I aortic dissection: analysis of the German Registry for Acute Aortic Dissection Type A. J Thorac Cardiovasc Surg 2012;144:617-23.

4. Jakob H, Dohle D, Benedik J, et al. Long-term experience with the E-vita Open hybrid graft in complex thoracic aortic disease. Eur J Cardiothorac Surg 2017;51:329-38.

5. Czerny M, Barchichat I, Meszaros K, et al. Long-term results after proximal thoracic aortic redo surgery. PLoS One 2013;8:e57713.

6. Borst HG, Walterbusch G, Schaps D. Extensive aortic replacement using "elephant trunk" prosthesis. Thorac Cardiovasc Surg 1983;31:37-40.

7. Committee for Scientific Affairs, The Japanese Association for Thoracic Surgery, Shimizu H, et al. Thoracic and cardiovascular surgery in Japan in 2016: Annual report by The Japanese Association for Thoracic Surgery. Gen Thorac Cardiovasc Surg 2019;67:377-411.

8. Shimizu H, Hirahara N, Motomura N, et al. Current status of cardiovascular surgery in Japan, 2015 and 2016: analysis of data from Japan Cardiovascular Surgery Database. 4-Thoracic aortic surgery. Gen Thorac Cardiovasc Surg 2019;67:751-7.

9. Verhoye JP, Belhaj Soulami R, Fouquet O, et al. Elective frozen elephant trunk procedure using the E-Vita Open Plus prosthesis in 94 patients: a multicentre French registry. Eur J Cardiothorac Surg 2017;52:733-9.

10. Ma WG, Zhu JM, Zheng J, et al. Sun's procedure for 
complex aortic arch repair: total arch replacement using a tetrafurcate graft with stented elephant trunk implantation. Ann Cardiothorac Surg 2013;2:642-8.

11. Roselli EE, Soltesz EG, Mastracci T, et al. Antegrade delivery of stent-grafts to treat complex thoracic aortic disease. Ann Thorac Surg 2010;90:539-46.

12. Tian DH, Wan B, Di Eusanio M, et al. A systematic review and meta-analysis on the safety and efficacy of the frozen elephant trunk technique in aortic arch surgery. Ann Cardiothorac Surg 2013;2:581-91.

13. Katayama K, Uchida N, Katayama A, et al. Multiple factors predict the risk of spinal cord injury after the frozen elephant trunk technique for extended thoracic aortic disease. Eur J Cardiothorac Surg 2015;47:616-20.

14. Tsagakis K, Wendt D, Dimitriou AM, et al. The frozen elephant trunk treatment is the operation of choice for all kinds of arch disease. J Cardiovasc Surg (Torino) 2018;59:540-6.

15. Shrestha M, Martens A, Kaufeld T, et al. Single-centre experience with the frozen elephant trunk technique in 251 patients over 15 years. Eur J Cardiothorac Surg 2017;52:858-66.

16. Roselli EE, Rafael A, Soltesz EG, et al. Simplified frozen elephant trunk repair for acute DeBakey type I dissection. J Thorac Cardiovasc Surg 2013;145:S197-201.

17. Poon SS, Tian DH, Yan T, et al. Frozen elephant trunk does not increase incidence of paraplegia in patients with acute type A aortic dissection. Rev Port Cir Cardiotorac Vasc 2020;27:9-10.

18. Preventza O, Liao JL, Olive JK, et al. Neurologic complications after the frozen elephant trunk procedure: A meta-analysis of more than 3000 patients. J Thorac Cardiovasc Surg 2019. [Epub ahead of print].

19. Leone A, Beckmann E, Aandreas M, et al. Total aortic arch replacement with frozen elephant trunk technique: Results from two European institutes. J Thorac Cardiovasc Surg 2020;159:1201-11.

20. Chu MWA, Losenno KL, Dubois LA, et al. Early Clinical Outcomes of Hybrid Arch Frozen Elephant Trunk Repair With the Thoraflex Hybrid Graft. Ann Thorac Surg 2019;107:47-53.

21. Chen Y, Ma WG, Zhi AH, et al. Fate of distal aorta after frozen elephant trunk and total arch replacement for type A aortic dissection in Marfan syndrome. J Thorac Cardiovasc Surg 2018. [Epub ahead of print].
Cite this article as: Okita Y. Frozen elephant trunk with Frozenix prosthesis. Ann Cardiothorac Surg 2020;9(3):152-163. doi: $10.21037 /$ acs.2020.03.13 